\title{
Measuring and managing liquidity risk in the Hungarian practice ${ }^{1}$
}

\author{
Balázs Árpád Szücs \\ PhD candidate, Department of Finance, Corvinus University of Budapest \\ E-mail: balazsarpad.szucs@uni-corvinus.hu
}

\begin{abstract}
Kata Váradi
Assistant Professor, Department of Finance, Corvinus University of Budapest

E-mail: kata.varadi@uni-corvinus.hu
\end{abstract}

The crisis that unfolded in 2007/2008 turned the attention of the financial world toward liquidity, the lack of which caused substantial losses. As a result, the need arose for the traditional financial models to be extended with liquidity. Our goal is to discover how Hungarian market players relate to liquidity. Our results are obtained through a series of semistructured interviews, and are hoped to be a starting point for extending the existing models in an appropriate way. Our main results show that different investor groups can be identified along their approaches to liquidity, and they rarely use sophisticated models to measure and manage liquidity. We conclude that although market players would have access to complex liquidity measurement and management tools, there is a limited need for these, because the currently available models are unable to use complex liquidity information effectively.

Keywords: market liquidity, portfolio optimization, semi-structured interview

JEL-codes: G11, G32

\section{Introduction}

In times of crises, it is usually plummeting prices that cause most of the concerns to market players. Whoever holds long positions in investment type assets loses money, but still, the fall of prices is neither the only, nor the best indicator for crises. It can be observed that no matter what direction of price movements represents the crises, liquidity falls every time. This was true for the crisis of 2007/2008, where the crisis was not only a financial crisis, but a liquidity and real economy crisis as well (Marer 2010).

\footnotetext{
1 Acknowledgement: The authors thank the Budapest Stock Exchange and MSCI for their support. The interview series was supported by the Budapest Stock Exchange, the subsequent research was supported by MSCI. The authors also thank the interviewees for their cooperation. Finally, the authors thank Edina Berlinger, Ákos Gyarmati, Márton Michaletzky and Gábor Völgyes for assistance in conducting the interviews.
} 
Normally different market players may value any asset a little differently which allows trade to happen. But in crises, these subtle differences in valuation lose importance, and the majority of the market refuses to take the losing side of the trades, which results in less frequent deals.

The aim of this paper is to present the findings of a semi-structured interview series on how Hungarian market players relate to liquidity. We have focused only on professional market players on the financial market who execute investment decisions, such as different kinds of portfolio managers, brokers and traders. Although risk managers also contribute to the trading needs of a company, they usually delegate the actual execution to the traders, and therefore only rarely consider liquidity issues themselves. Since the main focus of our research was to find out how those professionals, who do the actual execution, define liquidity, how they measure it, whether they consider it when making portfolio decisions, and finally, how they manage liquidity risk. We also studied whether different market participants, investor groups could be identified along these dimensions.

Past crises have demonstrated the severe consequences of ignoring liquidity risk. This is why both market players and researchers have paid increasing attention to consider and manage liquidity risk, which implies that traditional models of asset pricing and risk management must be extended to include markets with finite liquidity. We interviewed market players to explore their approach to these issues, which we intend to use in a subsequent research that extends asset pricing and risk management models with the concept of liquidity. Examining the heterogeneity of the players' approach to liquidity and classifying them accordingly will help us to create such models later on.

We set up our research in order to test the extent to which the results of the international literature apply to Hungarian markets. As a result, the following research questions were formulated.

- RQ\#1: Do market players interpret and measure liquidity similarly to the recommendations of the literature?

- RQ\#2: What methods do market players use to manage liquidity risk?

- RQ\#3: What are the popular execution strategies among market players?

We chose the qualitative method of semi-structured interviews to explore these questions. We believe it is the most suitable tool to find out how market players of the Hungarian economy relate to liquidity and liquidity risk.

The paper is structured as follows. Section 2 presents the current approach of the literature regarding the definition and measurement of liquidity, and the management of liquidity risk. Section 3 gives an overview on the semi-structured interviews that we employed. Section 4 presents our detailed findings, while section 5 concludes.

\section{Market liquidity}

The notion of liquidity has numerous interpretations. There is literature for example on the liquidity of corporations (e.g. Havran 2010), as well as on the liquidity of the entire financial 
sector (e.g. Shin 2005). Another example can be Brunnermeier and Pedersen (2009) who differentiate between funding liquidity and market liquidity. This paper only focuses on market liquidity, since this is the risk market participants face while trading. The literature on market liquidity is getting increasingly widespread. Accordingly, our literature review focuses only on the research that facilitates the understanding of the notions that occur in the interviews. So this section is built up as follows: first we introduce the concept of market liquidity, then we explain the indicators which are mentioned in the interviews, and finally present a few methods to manage liquidity risk.

\subsection{The concept of liquidity}

The focus of our research is the liquidity of financial markets, or in other words, market liquidity. In terms of definitions our starting point is the one provided by the Bank for International Settlements: (BIS 1999: 13): "Liquid markets are defined as markets where participants can rapidly execute large-volume transactions with little impact on prices."

Accordingly, a trader who takes liquidity into consideration must decide along three dimensions of the transaction, which are (Acerbi et al. 2011):

- Q: the volume/quantity of the order to be submitted,

- T: maximum time span of the deal to be fully executed,

- C: the loss suffered due to price changes, given Q and T.

Market liquidity could be described through the trade-offs among the above variables as shown in Figure 1.

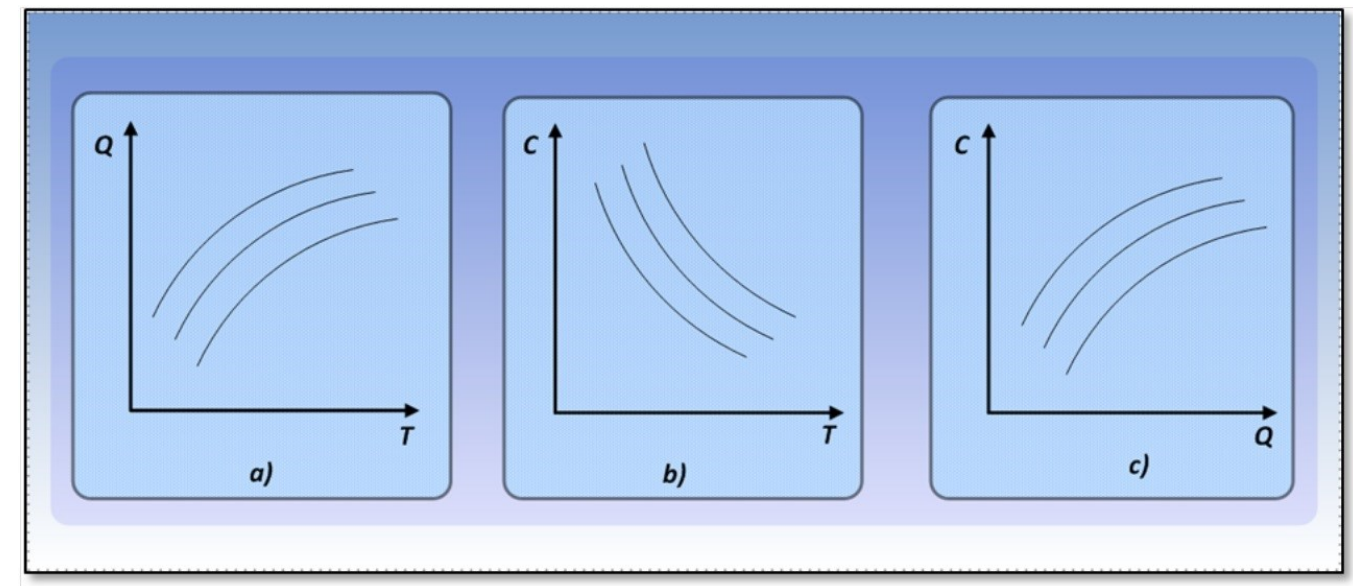

Figure 1. Trade-offs between time $(T)$, quantity $(Q)$ and adverse price effect $(C)$

Source: authors

For example, an impatient trader can choose an immediate buy or sell transaction through a market order, risking losing on the price, whereas a patient trader can submit a series of market orders with smaller quantities to avoid losses on the transactions due to the price 
changing effects of large-volume deals. This latter strategy reflects an awareness of the price impact. Dividing a large order into several smaller ones is a solution that is often called order splitting. It is represented in Figure 1b, where the overall quantity is fixed, and the smaller bits an order is split into (and thus the longer it takes to trade it), the smaller price effect it will have. It has to be noted, that order splitting may include not only market orders but limit orders $^{2}$ as well.

\subsection{Measuring liquidity}

The definition of liquidity suggests that its concept is complex enough to have no single best way to measure it. A comprehensive overview of liquidity indicators is provided by von Wyss (2004). Csávás and Erhart (2005) classify liquidity indicators into three categories based on (1) transaction costs, (2) transaction volume and (3) prices. Although they list several indicators in each group, we only elaborate on the ones that were mentioned in the interviews, namely the (relative) spread, and the turnover.

The spread and the relative spread are both indicators based on transactions costs. Clearly, the smaller these measures, the higher the liquidity of the asset. The spread is computed as follows: Spread $_{t}=p_{t}^{A s k}-p_{t}^{B i d}$, where $p_{t}^{A s k}$ denotes the best ask, and $p_{t}^{B i d}$ the best bid price at time $t$. This measure displays the loss realized when buying and then immediately selling the same asset. A variant of this is the relative spread: SSpread $_{t}=\frac{p_{t}^{A s k}-p_{t}^{B i d}}{\frac{1}{2}\left(p_{t}^{A s k}+p_{t}^{B i d}\right)}$, which determines the spread to mid-price ratio. ${ }^{3}$

The turnover is a volume based indicator. A greater turnover value indicates higher liquidity, because the more trades there are, the easier it is to find counterparties for a transaction. Turnover is calculated as: $V_{t}=\sum_{i=1}^{N_{t}} p_{t}^{i} q_{t}^{i}$, where $p$ denotes the price, $q$ the volume of the $i^{\text {th }}$ trade during time period $t$. Turnover is sometimes defined as the ratio of traded volume to total shares outstanding (TSO): $V_{t}^{\prime}=\frac{q}{T S O}$, which is a different but equally useful interpretation.

\subsection{Managing liquidity risk}

During the crisis of $2007 / 2008$ the importance of liquidity became widely recognized. Measuring and managing liquidity risk was the question most market players shared an interest in, including regulatory authorities, investors or even scientific researchers.

\footnotetext{
${ }^{2}$ Unlike market orders, a limit order specifies a price to trade at, thus it is usually not immediately executed.

${ }^{3}$ Another variant of the spread is the Xetra Liquidity Measure (XLM) that has been created for the Deutsche Börse Group by Gomber and Schweikert (2002). The same measure is employed on the Budapest Stock Exchange under the name of Budapest Liquidity Measure (BLM). See Kutas and Végh (2005), Gyarmati et al. (2010a).
} 
In response to the crisis, an important step forward in the regulation of financial institutions was the third of the Basel Accords (Basel III) that eliminated the deficiencies of the earlier versions. The most important amendment was the one that made banks obliged to include the costs and risks of liquidity into their pricing and performance evaluation models, as well as into the approval process of any new product (Basel Committee 2008). Our research however disregards the liquidity of financial institutions, and turns towards investors and their way of managing liquidity risk. Below we introduce two tools available to market players which they could use in their everyday activities to measure and manage liquidity risk. First, the use of the Liquidity Adjusted Value-at-Risk (LAVaR) models, and second, the modelling and estimating of price impact functions. Accordingly, we investigate during the interviews whether and to what extent market players use such models. There is however another, nonmodel based, but still very commonly employed way to manage liquidity risk in practice, namely the appropriate selection among the wide range of order types. This aspect is covered in subsection 2.4 below.

The essence of the LAVaR models is that it extends the regular Value-at-Risk (VaR) models ${ }^{4}$ to include liquidity risk. Regular $\mathrm{VaR}$ calculus only treats price risk, which is, besides liquidity risk, only one component of market risk. VaR has the assumption that in a given time frame one can trade any asset at the mid-price, which is usually not true under real market circumstances. This deficiency has to be fixed by allowing the possibility of trading at prices that are different from the mid-price, which is equivalent to seizing liquidity risk. Research shows that liquidity risk amounts for a remarkable proportion of market risk, which makes it worth to be taken into account. For example Lawrence and Robinson (1997) found that ignoring liquidity risk can result in underestimating the VaR by up to 30 percent.

LAVaR models are widely used in the literature, extending the regular VaR in different ways. All these models may be useful for market players when managing liquidity risk. They can be categorized as follows. ${ }^{5}$ The first set of models are based on order book data. There are several variants of these, such as models including exogenous liquidity risk (Bangia et al. 1998; Radnai - Vonnák 2009), models including endogenous liquidity risk (Francois-Heude Wynendaele 2001; Gyarmati et al. 2010b), and models based on transactions or volumes (Berkowitz 2000). The other type of models are based on optimal execution. Within this category, one can differentiate between models based on stochastic time horizons (Lawrence - Robinson 1996), and models based on modelling price impact functions (Jarrow Subrahmanyam 1997).

Besides LAVaR models, the Price Impact Functions (PIFs) can also provide useful information to market players. These functions show the relative price change of a given order on the market (Bouchaud et al. 2008; Gabaix et al. 2003). The two major categories are the virtual and the empirical PIF.

\footnotetext{
${ }^{4} \mathrm{VaR}$ shows the maximum possible loss of a position under a given significance level and time span (Jorion 2007).

${ }^{5}$ We highlight the LAVaR model which was first released in every category, together with the related Hungarian research we found.
} 
The virtual PIF (vPIF) is a function that ceteris paribus shows the expected price changes of a certain order submitted immediately. This approach treats the order book as unchanged in its state at the start of the observation.

The empirical PIF (ePIF) on the other hand is the one that can actually be observed on the market. This approach allows the order book to change, as it in fact does as different orders arrive through time, since the observer is not the only actor on the market. The ePIF is determined by two factors: 1) the amount of the expected price change given different volumes, and 2) the probability the price change will occur at all. The latter is not certain, as further limit orders may arrive in the meantime that can absorb the full order. The ePIF thus can be thought of as the conditional expected value of the vPIF (Bouchaud et al. 2008).

Awareness and analysis of the PIF can provide market players with important information on market liquidity. This information is essential while dynamically optimizing portfolio composition, where liquidity is the stochastic underlying process that determines collateral transaction costs arising from the lack of liquidity. An investor which tries to minimize costs must optimize along the dimensions of price effect, time and volume, as shown in Figure 1.

Consequently, PIFs are indispensable for any market player who tries to execute orders optimally. During the interviews, we tried to discover the execution strategies of investors, and whether they employ the PIF when determining these strategies. Alternatively, in case they do not use strict formalism, we are equally interested in how they forecast liquidity, and what they base their execution and order splitting strategies on.

\subsection{Order types}

Each market has its own microstructure and that is what all the market players can operate with. Most of them make use of all the possibilities, but some patterns can still be noticed, showing that certain player types tend to choose some options more often than others. This subsection enumerates the most commonly used order types as reported by our interviewees. Market and limit orders as the basic order types on order driven markets were mentioned earlier.

Traders and brokers often receive orders from their clients that set an upper limit to the daily traded volume. This is usually done by setting a maximum ratio to the full traded volume of the entire market on each day. For example, a 1/3 ratio would mean that the broker should respond to every trade on the market by submitting one of his own, but with half the volume. This order type is most common on relatively illiquid markets.

The over-the-day type order must be completed by the end of the trading day. This is also more frequent on rather illiquid markets.

On liquid markets, in contrast, the VWAP type orders are more popular, that require the broker to reach the Volume Weighted Average Price of a given time period - from 10am to $12 \mathrm{am}$ on the trading day for example. The curiosity of VWAP orders is that the broker commits to reach the VWAP before the specified period begins, but the actual VWAP can only be calculated ex post, that is after the specified period is over. 
Portfolio managers share an interest with traders in terms of using VWAP type orders, as well as the type where the upper volume limit is set relative to the overall market volume. There are, however, some other types that are rather common among portfolio managers, but according to our interviews, much less common among traders.

The first one is the stop-loss order that is idle while things are going well, but when the market price reaches a predefined threshold, the stop-loss is activated automatically and positions are closed in order to prevent further loss.

The second is the market-on-close order that is a simple market order that specifies the submission time to be a few moments before market closure.

The third type is the iceberg order, which is used when there is a large trading need that is worth hiding from the rest of the market. For example, if the fund manager has a large latent buy order, he submits it as an iceberg order, so only a fraction of the full volume will appear on the bid (as a buy limit order in the book). If this volume is traded, then it will automatically be replaced with a subsequent bid. If there is a significant interest on the sell side, and the best price level is cleared, the iceberg will instantly place a bid on the second price level. Finally, if there is a large volume on the ask, the iceberg will hit it with a market order.

The fourth type is the block order, which is arranged outside the exchange. It is used when a market player has a large trading need, but does not want to wait, neither to move the price significantly with a single large order. In such cases the broker searches a counterparty outside the exchange, and the parties agree on the price and quantity (Budapest Stock Exchange n.d.; NYSE n.d.).

\section{Interviews}

The interviews took place during 2011 and 2012, after the hardest time of the 2007 crisis was over. When selecting the interviewees we were striving for diversity. A total of 12 interviews were conducted, which included 8 portfolio and fund managers managing funds that range from 0.2 to 800 billion HUF, and 4 traders and brokers.

We tried to cover all major segments where investment decisions are executed, such as retail banks, investment banks, brokerage firm, etc. All interviewees had been active players on the market for 5-10 years, with decision rights on portfolio composition. The 12 interviewees were affiliated with 9 different institutions. A detailed list of interviewee types (without their identities) is provided in Appendix 1.

We did not specify the number of interviews in advance. Our concept was to keep organizing further interviews until major ideas started recurring in all the topics covered in our list of questions shown in Appendix 2. We stopped at 12, because although the particular stories and implications were always special, the essence of the answers began to be similar to those heard in one or the other earlier occasions.

While in the process, we found that brokers/traders tend to think similarly in terms of liquidity, whereas fund/portfolio managers differ more, depending on their styles being active 
or passive, technical or fundamental. Hence the overweighting of fund managers in our sample.

The interviewees trade Hungarian and international markets of futures, treasury bonds, shares, foreign exchange, commodities and derivatives. They all specialize to some extent, but they jointly cover all major markets.

\section{Results}

Our basic interest was to find out how market players relate to liquidity. Firstly, how they perceive and measure it (RQ\#1), secondly, how they manage the liquidity risk that occurs during their activities (RQ\#2), and finally, what the most commonly employed execution strategies are (RQ\#3). We found that the following four types of players had somewhat different approaches.

1. Traders/brokers,

2. Active fund managers operating on the basis of technical analysis,

3. Active fund managers operating on the basis of fundamental analysis,

4. Passive fund managers that follow benchmarks.

In sections 4.1-4.3 we show how these different market players measure and manage liquidity risk and what strategies they use in order to decrease the losses caused by illiquidity on the market.

\subsection{Liquidity - perception and measurement (RQ\#1)}

Traders usually need to execute orders rather quickly. If they are mediating for a client, they do not have their own supply or demand, they just try to achieve the most favourable execution possible. Day traders are different, because they speculate with their own money, but they also fall in this same category in terms of trading behaviour, because they typically do not have open positions overnight, and order execution is key for them too.

Traders consider a market liquid, if positions can be opened/closed quickly without (significantly) moving the price. In order to tell whether a market is liquid, they monitor the spread, the traded volume and the depth of the limit order book. ${ }^{6}$ Although one of them noted:

Turnover based estimation of liquidity may be misleading if the sample includes large pre-arranged bilateral transactions. In such cases liquidity information extracted from daily turnover data is likely to be distorted.

Fund managers relying on technical analysis have an approach that is very similar to that of the traders. They still trade rather frequently, but not as often as traders do of course. The most important difference to traders is that they open positions for longer periods, that is not only overnight, but for several days, weeks, sometimes even longer. They try to ride trends

\footnotetext{
${ }^{6}$ For more details on the limit order book and for market and limit orders see: Váradi (2012).
} 
that are forecasted through analyzing the charts. On top of what traders monitor, technical fund managers also look at the opening hours of markets (the longer the more liquid). They also noted that liquidity in fact cannot be treated separately, since: "Trend, volatility and liquidity matter equally."

Fund managers relying on fundamental analysis select a number of assets they are interested in, analyze them very thoroughly, and then decide whether they want to build up a long position in them or not. These assets are very often shares, but they also have other asset classes in their portfolios for different reasons.

Even if their funds are open ended, they typically invest for the long run. They go long in assets they believe are undervalued, and hold them until the mispricing disappears. This is why their perception of liquidity is interpreted via comparing transaction costs to mispricing. When buying, an asset is considered liquid if most of the mispricing does not have to be sacrificed through transaction costs. A few percentage points of loss on the transaction is irrelevant when they intend to hold the asset for years and expect the price to double or triple throughout that period. If they were wrong though, it should be possible to close (sell) the position with reasonable loss.

Mispricing is more probable in assets that are out of the direct focus of the market that is assets that are analyzed by fewer experts, which results in lower liquidity. From our viewpoint this is partly why they view liquidity a little differently than traders.

The price of these fairly illiquid shares usually moves away when a fund manager starts to build up a large position in it. They are often forced to split the order and keep accumulating for days, weeks or sometimes even months. A special measure of liquidity they mentioned is one that expresses how far they should reach in the book to build up a position immediately. If only two ticks are swiped out, the asset is fairly liquid, but if 6-7 ticks are cleared, then not so much.

For some of them, liquidity is more of a relative term:

If turnover today is double compared to the previous day, but the depth of the book has also doubled, then the increase in turnover leaves the liquidity unchanged. It is only the market's interest in the asset that has grown.

Passive fund managers that follow benchmarks commit to provide yields similar to a certain proxy, often some indices. This is basically a passive strategy that does not try to beat the market. Accordingly, for some fund managers if an asset is in the index, that is liquid enough already, because only liquid assets are selected to be part of any index.

Some fund managers follow benchmarks a bit more actively, and allow for tracking errors that are a little larger than usual. For them, liquidity is perceived similarly to traders, that is, liquidity means they are able to switch between overweight and underweight without significantly moving the price. 
In order to be able to buy or sell an asset reliably throughout the day, "The predictability of the market is important. If there is a direction in the morning, it should persist throughout the day."

In sum, according to the different answers it appears that market players try to optimize their execution along the volume - time - price impact $(\mathrm{Q}-\mathrm{T}-\mathrm{C})$ dimensions presented in section 2.1, but they all place their emphasis a little differently, which leads to somewhat different interpretations of liquidity. This problem expanded with asset selection renders the optimization very complicated.

\subsection{Liquidity management (RQ\#2)}

Traders, especially day traders manage liquidity risk by selecting the assets that are liquid enough for their purposes beforehand, and then trade only those. Liquidity risk is thus eliminated from their everyday practice. Brokers that trade for their clients cannot select the assets, because they are told what to trade, and usually have a fairly short time interval to do so. What they can do is mixing limit and market orders, try some order splitting, or search for blocks outside the exchange.

The intrinsic risk attitude of traders may be biased by their employer, for example: "Traders [in a bank] tend to seek risk more than others, because the bank rewards positive returns, but does not penalize negative ones."

Though traders try to eliminate liquidity risk by choosing only liquid securities, it doesn't mean that they can avoid every risk. For example if a trade has a 1/3 order (see section 2.4), it may quickly lead to extreme prices provided that several similar ones appear simultaneously three $1 / 3$ ratio orders for example. The way traders handle this risk is usually by adding a price barrier to such orders, beyond which the broker should not trade, even if the volume limit is not yet reached.

Technical fund managers manage their (not liquidity related) risk primarily via stop-loss orders. They place their stops very tightly which ensures they hardly hold positions that are losing value. The primary advantage of technical analysis lies exactly in this risk management: "The technical analyst knows he was wrong when his stop is hit. The fundamental analyst never knows ..."

According to the technical fund managers, their most substantial liquidity risk is the risk of the asset price jumping over the stop price, leaving them with a greater loss than expected. This can happen for at least two reasons. First, if the asset is not liquid enough, there might not be orders on every tick around the best prices. If the stop happens to be at a tick where there is no order, it will necessarily be jumped over. The second reason is the gap risk. Any market may open with a gap, that is the closing price of a day may be different from the opening price of the next trading day. If this happens, there is a chance that the stop will be jumped over.

A common way to manage the first problem is to select exclusively the most liquid assets, and trade only those. This ensures that there will be enough orders on absolutely every tick, and the problem is completely eliminated beforehand. The second problem can be alleviated by 
selecting markets that have long opening. Technical fund managers often select markets that are continuously open, that is from $8 \mathrm{am}$ on Mondays to $10 \mathrm{pm}$ on Fridays, because this way the gap risk only occurs on weekends, and not every day. This weekend risk is still so determining to them, that some of them said they would double the size of their open positions, should this weekend risk not be there.

Only some of them engage in illiquid assets, and when they do so, they manage the liquidity risk by position sizing, that is they open significantly smaller positions than they normally would on liquid markets. Another thing they can do on such markets is investing with no leverage.

Fundamental fund managers, as mentioned above, often engage in relatively illiquid assets, because that is where they think they have an edge, thus they may be forced to be accumulating these assets for long periods. Position sizing is a tool they use for managing liquidity risk. This means that the more illiquid the asset, the larger mispricing is needed to open any position.

Small caps often offer promising opportunities, but they also are illiquid most of the time. Fundamental fund managers want them in their portfolios anyway, but because their funds are often open ended, they must maintain a certain level of liquidity at all times. This can be achieved by buying loads of liquid assets aside that can be sold without loss if money is promptly needed. A second option is to hedge the small caps with indices, because it is much easier to short an index than to sell these small caps immediately that they had possibly been accumulating for months.

Unless absolutely necessary due to portfolio size, not using a risk management software is preferred:

We do not use risk management software, because we believe it takes room away from common sense. We think that reconsidering risk is skipped when such automatism is used.

Moreover they usually do not even measure risk at all, which means that they do not calculate Value-at-Risk, or even the simplest risk measure, the standard deviation. This is because they believe that the securities they invest in are fundamentally worth holding on the long run.

Passive fund managers might easily be forced into illiquid markets, because if the index itself is illiquid they have little choice. They have a number of routines though to handle these situations with.

They might engage in order splitting, but usually without strict rules, rather using some heuristics, or simply telling the broker to do it. Limit orders (in contrast to market orders) also provide an opportunity to achieve better prices, but it comes with the cost of longer waiting times. Block orders are always an option, although their success is conditional on the counterparties the actual broker can find.

They have settlements toward clients once a day. This means that their deadlines are usually at the end of the day, which provides them some freedom in their intra-day trading activity. Passive fund managers often use market-on-close orders. In some cases, fund managers may 
be interested in getting execution on the closing price. On the one hand, there may be speculative considerations, e.g. manipulating the closing price itself. On the other hand, those who follow a benchmark may easily assure this way that funds received during the day will have no initial tracking error (their performance is usually evaluated through closing prices). Any client that invests money into the fund on any day, will monitor the performance of the fund on the basis of the closing price of that day. The fund has no risk this way, because should the benchmark lose value, they just follow it. In contrast, if they wait for a few days before investing the money inflow, they run the risk of the benchmark moving away which may or may not be favourable to them.

Portfolio managers said they use special trading techniques to handle liquidity risk on the Hungarian government bond market. Their opinion is that the Hungarian government bonds have always been illiquid, and recently have become even more so. The same phenomenon was pointed out by the literature as well. Monostori (2013) stated that during the crisis of 2008-2009 the government bond spreads were increased by credit- and liquidity risk premia, but then in 2011-2012 the liquidity risk premia became less significant. A special trading technique reported for the government bonds is to invite exactly two counterparties, tell them both the sign and the value of the trade, and ask them to suggest prices knowing that there is another competitor. They have an incentive to give fair prices, otherwise they would lose significant business on that single large trade because the competitor would win it. Experience shows that prices move much less this way, compared to a case where wide publicity is given to the trade by inviting several counterparties.

A very pronounced liquidity management strategy was formulated in terms of the Hungarian stock market: "We refrain from Hungarian shares due to liquidity problems. Their markets dry out when they shouldn't, and they are traded under their fundamental value."

Another significant problem the passive fund managers have mentioned is that they have to face the bank holidays. Bank holidays somewhat differ from country to country, which may cause some trouble. If the fund has limit to a particular Exchange Traded Fund (ETF) emitter abroad for example, that has a bank holiday which is a regular weekday in Hungary, it may be very costly to buy the ETF from other sources. On these occasions the suspension of the fund might be a solution.

Finally, fund managers who are more active than others, who follow a benchmark may underweight some illiquid assets. Although this obviously increases the tracking error, it also reduces the liquidity risk which is a reasonable trade-off in certain cases.

\subsection{Executions strategies (RQ\#3)}

Traders and brokers have at least two different principles for opening a position. The first one is based on the daily life cycle of the market, where orders are split proportionally to daily traded volumes. This is common on illiquid markets, where there is little room for correction should the expectations of the trader prove to be false.

The second approach has the same starting point as the previous one, but the trader deviates from that proportional amount in virtue of her own expectations, which is safer to do on liquid 
markets, where subsequent corrections are much easier. A variant of this is to start with a large amount. If the market is beaten, then it is beaten substantially, and if not, the day is still there for trying to get back to the VWAP - depending on how much of a lag the trader can take on.

The "U" shape of traded volumes over the day is a common phenomenon on most markets that has to be thought of while trading. It refers to the observation of volumes being relatively high after the opening of the market, fall down around noon and rise again near the end of the trading day. Some explain this through the daily life cycle of people: they receive and react on new information in the morning, do other duties mid-day and close positions at the end of the day. Substantial intra-day information may of course alter this general pattern. In some countries (e.g. Turkey) markets even close around lunchtime.

VWAP orders were already mentioned previously. The fee paid to the trader is usually VWAP $+\mathrm{x}$ basis points, which motivates the trader to reach the VWAP and earn those extra basis points.

There are several possible strategies for trying to reach the VWAP (or better) on markets of different liquidities, but submitting the full amount as a market order at once is usually not one of them. Generally speaking limit orders are cheaper, but the time frame of the client's order does not always allow the trader to wait long enough for the limit orders to be cleared. In such cases, they submit limit orders, and only when they start running out of time do they submit some market orders to close the deal. This strategy has an average cost of half the spread.

If the market is liquid enough, market impact functions can be used to create algorithms that generate an optimal execution path, which will then determine the splitting scheme of the trade. This algorithm should take the other players into consideration, namely that they may notice that a large order is being fed to the market, and they could make use of this observation at the expense of the splitter. The algorithm should therefore try to be unrecognizable.

On rather illiquid markets, trading may easily become something similar to a poker game due to the limited number of players that are around simultaneously. The trader may 'have an edge' (i.e. some informational advantage) and come up with an idea about what is likely to happen on the market and then trade accordingly. It is important to hide their own strategy and at the same time try to figure out that of others, because knowing what others are up to can make all the difference. On such illiquid markets players may place orders simply to mislead the others sometimes. This strategy also provides some explanation to the "U" shape of daily traded volumes for the following reason. Instead of splitting gradually throughout the day, which would allow others to notice the splitting pattern, it is more favourable to submit a larger order in the beginning of the day, wait for the market to stop expecting a sequel, and submit the rest of their orders around the end of the day.

The relation between trading efficiency and the time horizon of investments was pointed out as follows: 
The shorter time intervals you trade, the more important math and statistics become. Timescale is the key. Those who trade every second exploit the inefficiencies of those who only trade once a day. Those who trade every day exploit the inefficiencies of the ones trading monthly, and so on. The longer the time scale, the more important fundamental analysis becomes.

Technical portfolio managers, as mentioned earlier, often manage liquidity risk by selecting the most liquid assets. Hence they usually do not amount for a large proportion of daily traded volumes, and thus can submit market orders freely without having to worry too much about price effect. Some of them, however, trade on illiquid markets sometimes, which is done by choosing limit orders.

A special interpretation on the timing of trades was phrased as follows: "It is best to buy when my stomach is trembling, because if I am afraid, then others are too."

Fundamental portfolio managers tend to trade illiquid markets, where the mispricing is potentially larger. On such markets it is not uncommon to have a trading plan that would significantly move the price if submitted immediately. One strategy they mentioned to handle this problem is to split the full order into pieces that are similar in size to those already present on the market, which means they try to hide their latent trading plan. They do not mind accumulating the asset for weeks if necessary, but they certainly do not want to drag the price away too much. They also avoid misleading or scaring the market with large transactions. Another solution is to look for blocks outside the market by asking their brokers, who also call them if someone is looking for blocks in an asset they often trade.

They also happen to use trading algorithms provided by their trading platform, for example one that always replaces their orders to keep them at the best prices on either side.

In terms of timing, the fundamental idea is that: "It is very easy to buy anything on capital markets. Selling is the art. And not only when, but how to sell."

Finally, according to a timing heuristic, if a relatively large order appears in the book of a small cap, it probably means that someone has lost their patience and submitted the entirety of their remaining order, which is worth hitting, because a sequel is rather unlikely.

Portfolio managers that follow a benchmark may also need to split their orders if large funds arrive in a short time interval. On these occasions, they either do the splitting in an ad hoc manner (relying of course on the experience of the fund manager), or simply let the broker do it within a specified time frame. In this latter case, the daily VWAP is usually good enough for the fund manager, but they often reach better prices than that.

They also use their trading platforms for splitting, for example the feature that splits the order into bits of 100 pieces, and submits them to various markets.

A timing consideration is that limit orders may take a while to be cleared, whereas amendments to the portfolio composition are urgent. Hence the market orders are preferred. A collateral aspect of this waiting time was phrased this way: "And we do not want to stay in the office very late anyway, and wait for the U.S. [market] to close." 


\section{Summary and conclusions}

In our research we investigated the market players' relation to market liquidity, especially the way they measure and manage it. Our first research question was whether they interpret and measure liquidity similarly to the recommendations of the literature. We found that the four investor groups, the (1) traders (2) technical-, (3) fundamental- and (4) passive portfolio managers use mainly the most simple liquidity indicators, like the spread, or the turnover. They do not use any complicated liquidity measures to quantify liquidty. In sum we can state that according to our results, they appear to interpret liquidity similarly to the approach presented in the literature.

Our second research quesiton explored the methods market players use to manage liquidity risk. We found that they tend to use rather simple ones, which together with their market experiences are still sufficient for them to manage their risk. Consequently, they ignore the more complex risk management tools, such as Liquidity Adjusted VaR or price impact functions. Some of them even neglect the simplest risk measures, like the standard deviation. The reason for this is obviously not their disability to gather sufficient information to produce these complex measures. We believe the main reason is the lack of appropriate financial models that could effectively employ such information, it is therefore not worth calculating these measuresat all. On the whole, liquidity risk is managed in fairly simple ways. Traders select markets where liquidity is not an issue. Technical fund managers use stop-loss extensively. Fundamental portfolio managers rely on common sense while evaluating liquidity risk. Finally, there is often nothing that passive fund managers could do when the benchmark becomes illiquid. In addition, the overall size of the Hungarian market is also too small for the worthy use of complex risk management software, and so are the individual participants of it. This means that the information compression of complex statistics might even backfire when the relatively small portfolios could be well managed simply through the use of common sense.

Finally, our third research question was about the popular execution strategies among market players. In terms of order types, traders often have to work with time, price or volume limits obtained from the client, which puts an exogenous constraint to the possible trades. Portfolio managers like the stop-loss and the market-on-close order depending on their attitude to markets, the use of which includes risk management aspects other than liquidity risk. Iceberg and block orders on the other hand, which are also used, can be considered as preventive actions to avoid liquidity problems in relation to upcoming trades.

When it comes to timing, traders often follow the "U" shape of the order book, because it limits their options to lossless trade mid-day. VWAP orders are common for them, because it is convenient to their clients. For technical portfolio managers timing is usually not so much of an issue because of their market selection. Fundamental portfolio managers often engage in order splitting spanning through a fairly long period of time, because the markets they trade on are rather illiquid. Order splitting is often necessary for benchmark following portfolio managers too.

According to the interview series, we conclude that although there is enough information available to employ complex liquidity measurement and even management tools, the problem 
is that financial theory lacks the appropriate models, which results in bounded information proceccing capacity. The investment problem itself is too complex for any model to fully cover. This is why market players attempt to simplify it to make it more transparent. There are two groups of variables that must be considered in portfolio decisions. First, "return volatility - liquidity", and second, "volume - time - price impact" (Q-T-C) together with asset selection $(\mathrm{X})$.

Our opinion, based on the interviews is that "return - volatility - liquidity" must be treated together when optimizing portfolio composition. In other words, the return (-premium) should compensate for the total market risk, that is not only for price, but also for liquidity risk. We could deduce from the interviews that the "volume - time - price impact - asset" dimension is important, because most investors intend to open optimal positions in not just a single asset, but an entire portfolio. Therefore the regular "volume - time - price impact" problem is extended with asset selection, considering all potential markets. As far as we are aware, there is no appropriate dynamic model to determine the optimal investment strategy with regard to liquidity for a single asset, let alone for an entire portfolio.

From our viewpoint any effort to reduce complexity is therefore justifiable. One way to do this is to eliminate the liquidity issue. For example (1) The trader selects the most liquid markets beforehand, and trades only those. (2) The fund manager delegates the liquidity problem to the trader. The inverse solution is that of the broker, who only deals with liquidity, and clients select the remaining parameters of the transaction.

In any of the cases above, one deviates from the optimal solution in exchange for an acceptable one, since optimizing on a narrower set results in possible loss of value.

\section{References}

Acerbi, C. - Stefek, D. - Szekeres, Z. (2011): Toward Liquidity Metrics. Financial Market Liquidity Conference. Budapest, 10-11 November 2011.

Bangia, A. - Diebold, F.X. - Schuermann, T. - Stroughair, J.D. (1998): Modeling Liquidity Risk With Implications for Traditional Market Risk Measurement and Management. Financial Institutions Center at The Wharton School Working Paper 99-06.

Bank for International Settlements (1999): Market Liquidity: Research Findings and Selected Policy Implications. Committee on the Global Financial System, Publications No. 11.

Basel Committee (2008): Principles for Sound Liquidity Risk Management and Supervision. Basel: Bank for International Settlement

Berkowitz, J. (2000): Incorporating liquidity risk into value at risk models. Working paper, University of California, Irvine.

Bouchaud, J-P. - Farmer, J.D. - Lillo, F. - des Meurisiers, O. (2008): How Markets Slowly Digest Changes in Supply and Demand. In: Hens, T. - Schenk-Hoppe, K. (eds) Handbook of Financial Markets: Dynamics and Evolution. Amsterdam: Elsevier. 
Brunnermeier, M. K - Pedersen, L. H. (2009): Market Liquidity and Funding Liquidity. The Review of Financial Studies 22(6): 2201-2238.

Budapest Stock Exchange (n.d.) Tőzsdei megbízások [Stock exchange orders] http://bet.hu/topmenu/befektetok/tozsde lepesrol lepesre/azonnali piacismeretek/hog yan_kereskedjunk_a tozsden/tozsdei_megbizasok, accessed 22 July 2014.

Csávás, C. - Erhart, S. (2005): Likvidek-e a magyar pénzügyi piacok? - A deviza- és állampapír-piaci likviditás elméletben és gyakorlatban [Are Hungarian Money Markets Liquid? - The Liquidity of the Foreign Currency- and the Government Security Market in Theory and in Practice]. MNB Working Paper 44.

Francios-Heude, A. - Van Wynandaeale, P. (2001): Integrating liquidity risk in a parametric intraday VaR framework. Working Paper.

Gabaix, X. - Gopikrishnan, P. - Plerou, V. - Stanley, H.E. (2003): A theory of power-law distributions in financial market fluctuations. Nature 423: 267-270.

Gomber, P. - Shcweikert, U. (2002): The Market Impact - Liquidity Measure in Electronic Securities Trading. Die Bank, 7/2002.

Gyarmati, Á. - Michaletzky, M. - Váradi, K. (2010a): Liquidity on the Budapest Stock Exchange 2007-2010. Budapest Stock Exchange Working Paper, http://ssrn.com/abstract=1784324, accessed 22 July 2014.

Gyarmati, Á. - Michaletzky, M. - Váradi K. (2010b): The Budapest Liquidity Measure and its application Liquidity Risk in VaR Measures. Budapest Stock Exchange Working Paper, http://ssrn.com/abstract=1784348, accessed 22 July 2014.

Havran, D. (2010): A vállalati likviditáskezelés [Corporate Liquidity Management]. Unpublished dissertation, Corvinus University of Budapest.

Jarrow, R. - Subrahmanyam, A. (1997): Mopping up liquidity. Risk 10(12): 170-173.

Jorion, P. (2007): Value at Risk: The Benchmark of Controlling Market Risk, 3.ed., McGrawHill Publishing Co.

Kutas, G. - Végh, R. (2005): A Budapesti Likviditási Mérték bevezetéséről [About the Introduction of the Budapest Liquidity Measure]. Közgazdasági Szemle 52(7-8): 686711.

Lawrence, C. - Robinson, G. (1997): Liquidity Measures. Risk 8(7): 52-55.

Marer, P. (2010): The global economic crisis: Impacts on Eastern Europe. Acta Oeconomica 60(1): 3-33.

Monostori, Z. (2013): Crisis on the Hungarian government bond markets in the winter of 2011-2012: Was there a liquidity problem? Society and Economy 35(4): 539-550.

NYSE (n.d.) NYSE Trading Information. http://www.nyse.com/pdfs/fact_sheet_nyse_orders.pdf, accessed 22 July 2014. 
Radnai, M. - Vonnák, D. (2009): Likviditási kockázat az Európai Tőkemegfelelési Direktíva tervezett módosításában [Liquidity Risk in the Planned Modification of the European Capital Adequacy Directive]. Hitelinztézeti Szemle 8: 248-256.

Shin, H.S. (2005): Financial System Liquidity, Asset Prices and Monetary Policy. The Changing Nature of Business Cycle Conference, Kirribilli, 11-12 July, 2005.

Váradi, K. (2012): Liquidity Risk on Stock Markets - Statistical Analysis and Possible Application of the Budapest Liquidity Measure. Unpublished dissertation, Corvinus University of Budapest.

Von Wyss, R. (2004): Measuring and Predicting Liquidity in the Stock Market. Unpublished dissertation, Universität St. Gallen.

\section{Appendices}

Appendix 1. - List of respondents

1. Quant trader

2. Institutional broker

3. Money market trader

4. Commodity trader

5. Technical analyst

6. Equity portfolio manager, technical analyst

7. Equity portfolio manager, fundamental analyst

8. Fixed income portfolio manager, fundamental analyst

9. Portfolio manager, fundamental analyst

10. Portfolio manager (passive)

11. Chief Investment Officer

12. Chief Executive Officer

\section{Appendix 2-Interview questionnaire}

We designed the interview questions to fit our scope of interest. They all refer to liquidity in one way or the other: either the perception and measurement of the notion of liquidity, or the management of liquidity risk. Some questions go into detailed issues, such as order splitting and portfolio liquidation problems. The questions were sent to each interviewee days before the actual interview took place.

The questions were the following:

1. How would you define the notion of liquidity?

2. When do you consider a market as liquid? 
3. How do you measure liquidity?

4. What indicators of liquidity do you monitor?

5. How do you take liquidity into account before making decisions of investment or trading?

6. If an exposure has to be reduced, do you consider liquidity issues?

7. What rules of thumb or heuristics do you use in relation to liquidity?

8. Do you use stop-loss? If you do, how do you decide where to put it?

9. In what situations do you prefer larger
a. ...loss caused by adverse price effect
b. ...time-span of execution?

10. Do you ever engage in order splitting? If you do, how do you do it? 